\title{
THE USE OF ACCOUNTING APPS VIA MOBILE CLOUD COMPUTING IN ROMANIA
}

\author{
Laura Elena Tudoran ${ }^{1}$ \\ Bogdan Ştefan Ionescu ${ }^{2}$
}

\begin{abstract}
In a world in perpetual motion and transformation, mobile devices tend to be communications universal remedy applicable throughout many spheres of activity.

Mobile devices are different from each other, depending on the information processing capacity, storage capacity, keyboard, screen, battery life and communication bandwidth. As cloud-based accounting solutions are serving consumers and users of financial accounting information we chose to evaluate the user experience of SaaS financial applications accessed from mobile devices from the perception PhD students participating in doctoral programs organized by the Academy of Economic Studies in Bucharest.
\end{abstract}

Keywords: cloud computing, mobile cloud computing, cloud accounting in Romania

JEL Codes: M41, O3

\section{Introduction}

Speed, computing power, storage, feature support and multiple user applications are just some of the features of mobile devices, which made them evolve considerably in recent years. As can be seen in Figure 1 below worldwide shipment of smart phones (equipped with a computing capacity and connectivity significantly higher than other mobile phones) have exceeded those of PC by approximately $86 \%$ in 2013 , according to studies conducted by IDC.

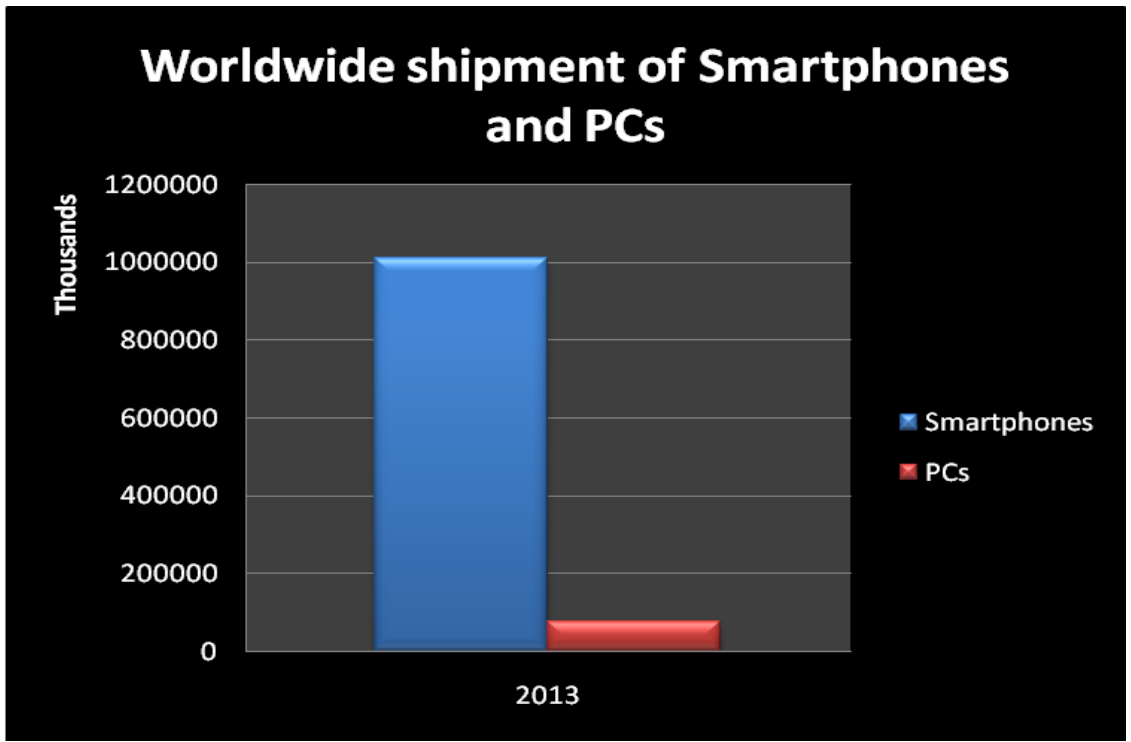

Figure no. 1 - Worldwide shipment of Smart phones and PCs in 2013 Source: IDC (2013)

\footnotetext{
${ }^{1}$ The Bucharest Academy of Economic Studies, Bucharest, Romania, e-mail: tudoranlaura@gmail.com

2 The Bucharest Academy of Economic Studies, Bucharest, Romania,e-mail: ionescub@gmail.com
} 
eMarketer estimates that $73.4 \%$ of users accessed the Internet from a mobile device in 2013. This is set to rise to $79.1 \%$ in 2014 and reach $90.1 \%$ in $2017.53 .8 \%$ of European users have accessed the Internet from a mobile device in 2013, eMarketer estimates that the number will increase to $70.1 \%$ in 2014 and $91.15 \%$ in 2017 . This data is a prerequisites for development and adaptation of mobile computing applications that need to keep up with mobile technology in terms of hardware and communications.

In this study we chose to evaluate the user experience of SaaS financial applications accessed from mobile devices from the perception $\mathrm{PhD}$ students participating in doctoral programs organized by the Academy of Economic Studies in Bucharest.

\section{Trends in information technologies}

Cloud computing has become a significant research subject in both industrial and scientific communities (Kottari et al, 2013), more than 226000 scientific articles were published from 2007 until today. Cloud computing dominates the list of the ten most important strategic technology trends provided by Gartner in 2014, which means that cloud computing will have an increased impact on the organizations in 2014.

Kottari et al (2013) justifies the rapid growth of cloud computing technology based on the inability of PCs to keep up with increasingly faster software, noting that the idea of "cloud" reduces the number of network connections and systems involved in online services.

The rapid evolution of the mobile market has made it a favorable environment for the spread of the concept of cloud computing. According to ABI Research, a technology market intelligence company focused on putting information into the hands of executives in order to enable them to make the right decisions on technology and market investment, "by 2015, more than 240 million business customers will use cloud computing services through mobile devices, generating revenues of 5.2 billion dollars."

Currently, applications created for mobile devices are becoming safer and more complex for cloud users and businesses. Global revenues from mobile networks reached 1.200 billion dollars in 2012 and it is estimated that the market size mobile cloud will exceed $\$ 45$ billion by 2016 .

\section{The challenge of mobile cloud computing paradigm of information}

Although mobile cloud computing is relatively new, dating back to 2007 its global popularity, as measured by Google Insights for Search by summarizing the searches on the topic, shown in Figure 2, is increasing since 2008.

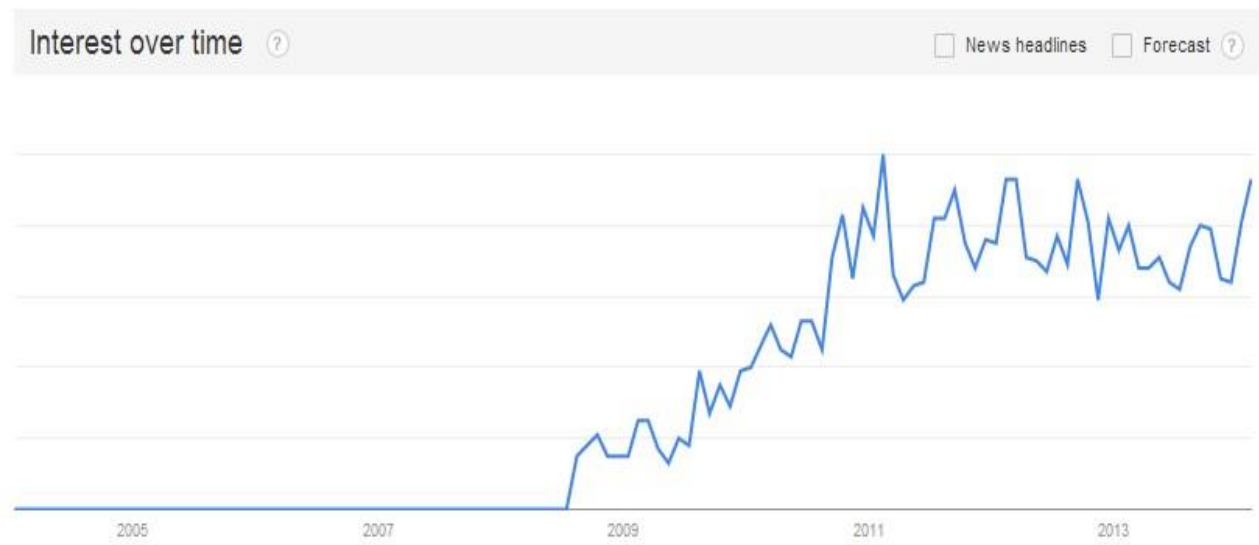

Figure no. 2 - Global popularity of mobile cloud computing

Source: Google Insights for Search (2014) 
Just as in the case of cloud computing technology, currently there are many definitions and interpretations for the concept of mobile cloud computing.

In 2010, Google's CEO Eric Schmidt described the mobile cloud computing in an interview as "based on the development of cloud computing, mobile phones will become increasingly complicated, and will evolve at a super portable computer".

According to Kottari et al (2013), mobile computing (MCC) has been presented as a potential technology for mobile services along with the explosive growth of the use of smart phones and their apps and the emergence of the concept of cloud computing. MCC integrates cloud computing in the mobile environmentand exceeds obstacles related to performance (e.g. battery life, storage capacity and bandwidth), medium (e.g., heterogeneity, scalability, and availability), and security (e.g, reliability and confidentiality) in mobile computing.

Mobile Cloud Computing Forum defines MCC as "mobile cloud computing, in its simplest form refers to an infrastructure that allows both data storage and processing outside their mobile device. Mobile cloud applications move the computing power and data stored away from mobile phones on a cloud,providing mobile computing applications not only to smart phone users but to a much broader range of mobile subscribers. "

According to Singh et al (2012), mobile cloud computing is the use of cloud computing technology combined with smart mobile devices. There is cloud computing where tasks and data are stored on the Internet, rather than on individual devices, providing access to application data.

According to Shastri et al (2013) and Park et al (2011), Mobile Cloud Computing is a combination of mobile computing, mobile Internet and cloud computing. Mobile computing means sharing resources and exchanging data between computers or other intelligent equipment such as mobile phones. Mobile cloud computing is the ability to provide valuable, accurate information and in real time to any user anywhere, anytime. Mobile Cloud Computing integrates the advantages of mobile computing, mobile networks and cloud computing, meaning that any intelligent device such as mobile phones and personal computers can receive services in a wireless environment. Mobile devices are different from each other, there are differences depending on the CPU processing capacity of the internal memory, keyboard, display, battery life and bandwidth. A major advantage of cloud computing is that cloud storage offers high capacity and high speed computing, as a group of servers within a network. Great results can be achieved when low-performance mobile devices can exchange data with the "cloud ". Marinelli (2009) states that the benefits of cloud computing can be fully deployed in mobile networks, storage and processing of applications is accomplished on the cloud thus reducing the performance requirements of mobile devices.

Dihal et al (2013) performed a comparison between traditional cloud computing and mobile cloud computing based on three key characteristics: connectivity, devices and services used. As can be seen in Table 1 unlike traditional cloud computing, mobile cloud computing benefits from limited connectivity to the internet.

Table no. 1

Cloud computing versus Mobile Cloud Computing

\begin{tabular}{|c|c|c|c|}
\hline Category & Factor & Cloud Computing & Mobile Cloud Computing \\
\hline \multirow{6}{*}{ Connectivity } & Network access & $\begin{array}{c}\text { Continuous fixed line } \\
\text { (possibly through local } \\
\text { Wi-Fi) }\end{array}$ & $\begin{array}{c}\text { Interrupted wireless depending on } \\
\text { MNO (mobile network operator) } \\
\text { coverage or available ad-hoc Wi- } \\
\text { Fi or Bluetooth connections }\end{array}$ \\
\cline { 2 - 4 } & Network bandwidth & High and constant & $\begin{array}{c}\text { Currently limited, variable } \\
\text { dependent on network coverage } \\
\text { and user movement speed }\end{array}$ \\
\hline
\end{tabular}




\begin{tabular}{|c|c|c|c|}
\hline Category & Factor & Cloud Computing & Mobile Cloud Computing \\
\hline & Network latency & $\begin{array}{c}\text { Typically } \sim 8-35 \mathrm{~ms} \text { from } \\
\text { user to DSL/Cable ISP }\end{array}$ & $\begin{array}{l}\text { Typically } 100 \mathrm{~ms} \text { due to mobile } \\
\text { network latency }\end{array}$ \\
\hline & Network data plans & Flat rate & $\begin{array}{l}\text { Trend towards data caps (De } \\
\text { Vries, 2011) possibly } \\
\text { differentiated fees per type of use } \\
\text { depending on net neutrality }\end{array}$ \\
\hline & Location & Fixed & Variable: on the move of fixed \\
\hline \multirow{3}{*}{ Devices } & Devices used & $\begin{array}{l}\text { Desktop computer, } \\
\text { laptop computer }\end{array}$ & laptop, tablet, smart phone, etc. \\
\hline & Devices properties & $\begin{array}{l}\text { Standardized input } \\
\text { methods, large displays, } \\
\text { large resource pool in } \\
\text { case of thick clients, } \\
\text { scarce resources for thin } \\
\text { clients } \\
\end{array}$ & $\begin{array}{l}\text { Currently limited battery life, } \\
\text { processing power, storage } \\
\text { capacity and memory, varying } \\
\text { form factors like screen size, } \\
\text { input methods, fragmented OS } \\
\text { and web interfaces }\end{array}$ \\
\hline & Devices sensors & $\begin{array}{l}\text { Microphone, camera, } \\
\text { light sensor (on laptops) }\end{array}$ & $\begin{array}{l}\text { GPS, camera, microphone, } \\
\text { proximity sensor, light sensor, } \\
\text { barometer, NFC, gyroscope, } \\
\text { accelerometer }\end{array}$ \\
\hline \multirow[t]{2}{*}{ Services } & Service scope & $\begin{array}{c}\text { Anything from } \\
\text { applications to operating } \\
\text { systems and enterprise } \\
\text { resource planning } \\
\text { packages; in general all } \\
\text { service that can run on } \\
\text { business IT } \\
\text { infrastructure and } \\
\text { platforms } \\
\end{array}$ & $\begin{array}{l}\text { Limited due to service form } \\
\text { factor, wireless connectivity, } \\
\text { input and processing limitations }\end{array}$ \\
\hline & Service focus & $\begin{array}{l}\text { Full range of location } \\
\text { bound applications }\end{array}$ & $\begin{array}{l}\text { Mobile value services with a } \\
\text { focus on communication, } \\
\text { information, entertainment and } \\
\text { transaction services; business } \\
\text { applications and productivity } \\
\text { tools; location-aware, proximity- } \\
\text { aware applications }\end{array}$ \\
\hline
\end{tabular}

Source: Dihal et al, 2013

Both in the vision of Shastri et al (2013) and in the vision of Kottari et al (2013), mobile cloud computing features are:

1. Offloading computation:The next generation of mobile applications available in online stores specific to each type of mobile device forces the limit on how their users interact with the physical world and the cyber world. Currently, these mobile applications requires intensive computing capabilities that are inconsistent with the limited resources of mobile devices. This constraint is not just a temporary limitation of current technology, but it is intrinsic to mobility.

2. Overcoming limitations of the device's hardware: processing and storing data in the cloud significantly reduces the importance of the mobile device's computation capability, even mobile phones with a lower performance being able to perform mobile cloud computing. 
3. Processing speed and data storage: $\mathrm{MCC}$ will result in exceeding the limits of mobile devices, especially those related to processing power and data storage. This advantage is obviously due to the cloud's processing capacity. If the input interface and output data is sufficiently good task results can be directly observed using cell phones.

4. Convenient access to data: storing data in the cloud using cloud computing offers users on the one hand, a large space for data storage, and on the other hand, provides a convenient mechanism to access data by specifying that it will work as fluent as local if the bandwidth is sufficient.

5. On demand service for cost reduction: as the business environment is dominated by the Internet, customers have different needs. The personalized services can meet different needs of customers, but they often lead to a too high service load. Through cloud computing resources are shared among different services, effectively reducing service costs.

6. Removing regional restrictions: mobile cloud computing eliminates regional restrictions, allowing people to get what they want, at any time and any place on the internet.

7. Increased battery life: MCC could extend battery life by moving execution intensive processes in the cloud.

8. Improving reliability: data storage or running applications or cloud is an effective way to improve the reliability as backup data and applications are stored and saved on a number of computers, reducing the chance of being lost from mobile devices.

9. Security: MCC can increase the level of security for mobile devices by monitoring and maintaining software centrally.

According to Huang et al (2013), the MCC, a mobile entity can be considered either a mobile device or a mobile physical computing / storage software agent in a virtualized cloud resource provisioning. MCC differs its centers of interest based on the close interactionof Cyber Physical System (CPS) consisting of intelligent physical and mobile entities and Cyber Virtual System (CVS), consisting mainly of virtualized resources and cloud-based services.

Based on the classification methods for providing cloud services in Infrastructure-as-aservice (IaaS), Platform-as-a-Service (PaaS) and Software-as-a-Service (SaaS), guided by layers of virtualization and considering the involvement of CPS and CVS, we support the idea of Huang et al (2013) that the arrangements for the supply of mobile cloud services can be classified according to computational entities roles in the service. By doing this, arrangements for providing mobile cloud services include:

1. Mobile-as-a-Service-Consumer (MaaSC): is derived from the traditional client-server model plus the introduction of virtualization, fine-grained access control and other cloudbased technologies in the initial stage. Mobile devices can outsource their computing functions and cloud storage, in order to achieve improved performance. According to this architecture, mobile devices are consuming services. Most existing MCC services fall into this category.

2. Mobile-as-a-Service-Provider (MaaSP): unlike in MaaSC, the role of a mobile device is moved from one service consumer to service provider.

3. Mobile-as-a- Service-Broker (MaaSB): can be considered as an extension of MaaSP as it provides networking and data transport services to other mobile devices or detection nodes. MaaSB cloud's boundaries extend to mobile devices and wireless sensors. Thus, a mobile device can be configured as a gateway or proxy to provide network services via various communication approaches such as 3/4G, Bluetooth, WiFi, etc. Moreover, the mobile device proxy can provide an additional layer of security and confidentiality for sensors.

Both the vision of vision of Singh et al (2012) and in the vision of Kottari et al (2013) the challenges that mobile cloud computing needs to face are: 
1. The cost of cloud services and scalability: among the main advantages of using cloud services are eliminating capital expenditures and, depending on the elasticity of cloud computing, cloud's utility and pricing model, capacity scaling to different needs.

2. The cost of the mobile phone network and scalability: besides cloud operating expenses and high potential scalability concerns, CCM applications may require intense wireless network with implications for mobile network capacity, especially during periods of peak demand with a potential negative impact on network latency, packet loss and response time, with negative consequences on user experience. In addition, the requirement of high bandwidth data connection may increase prohibitively mobile data bills of mobile users, making it impractical for CMM applications.

3. Availability: As opposed to cloud computing, in MCC service availability is a more important issue as mobile users cannot connect to the cloud due to congestion, network failures or lack of signal.

4. Heterogeneity: MCC will be usedin extremely heterogeneous wireless network interfaces. Different mobile nodes access the cloud through different radio access technologies such as WCDMA, GPRS, WiMAX, CDMA2000 and WLAN. Hence the problem of managing wireless connectivity while fulfilling the requirements of MCC (e.g. maintaining connectivity, wireless connectivity on demand scalability and energy efficiency of mobile devices).

5. Offloading computationproblems: offloading is one of the main features of MCC to improve battery life of mobile devices and to increase application performance. However, offloading is not always the most effective way to save energy. To compile code downloading can consume more power than local processing when code size is reduced. For example, when compiling code size is $500 \mathrm{~KB}$ amended downloading consumes about $5 \%$ of the battery of a device for communication, while local processing consumes about $10 \%$ of the battery. In this case, the battery offloading can save up to $50 \%$. However, when the size is $250 \mathrm{~KB}$ modified codes, yield is reduced to $30 \%$. When the modified code size is reduced, downloads consume more battery than local processing.

6. Security: Mobile devices are exposed to numerous security threats such as malware (e.g., virus, worm, and Trojan horses). In addition, the integration of global positioning system (GPS) in mobile devices may cause privacy concerns for subscribers.

Applications that big companies use to conduct business operations such as accounting, business intelligence (BI), communication and collaboration, customer relationship management (CRM) and human resources (HR) are evolving under the pressure of difficult economic conditions and adaptation capabilities offered by cloud computing, mobility, data analysis of large data and social commitments.

According to the worldwide forecast on IT spending conducted by Gartner in March 2013 (Figure 3), enterprise software records a value of $\$ 296.6$ billion in 2013, with an annual growth rate of $6.4 \%$ compared to 2012. Enterprise software represents only $7.89 \%$ of total IT spending in 2013, while telecommunications is $44.8 \%$. 
2013 worldwide IT spending forecast (US $\$$ billions)

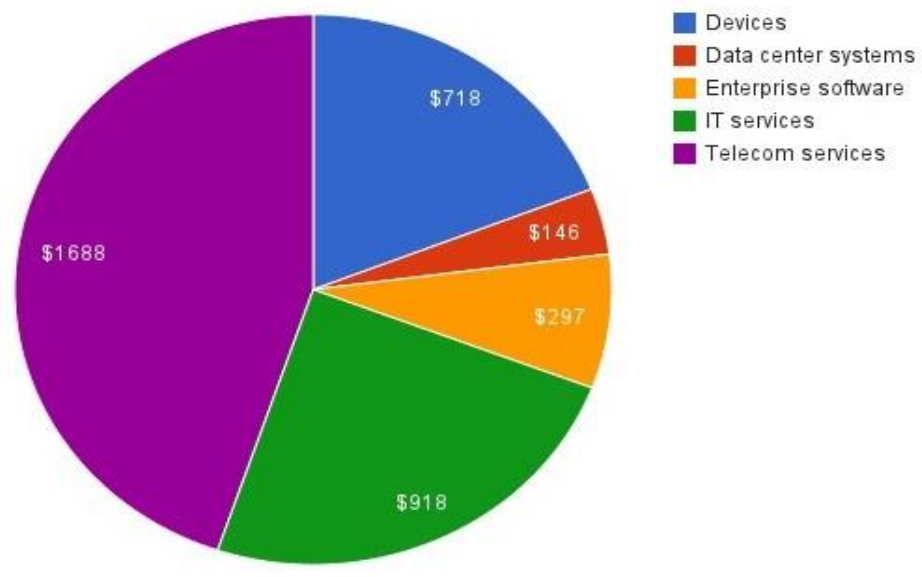

Figure no. 3 - 2013 worldwide IT spending forecast

Source: http://www.zdnet.com/the-evolution-of-enterprise-software-an-overview-7000014006/

As previously above, one of the solutions to successfully implement cloud computing technology in the economy is the "cloud accounting" technology derived from the "cloud computing" which allows the storage and processing of company financial and accounting documents in the cloud.

Accounting by cloud computing surpassed the research phase, many companies that provide accounting services via the cloud being active on the market. These include: e-contabilitate.ro, San Software, Software Expert Euro SRL (expertAccounts) and Wizrom.

IDC Romania researchand market analysis company conducted a study in 2010 on the Romanian market of Cloud Computing ("Romania Cloud Services 2011-2015 Forecast and 2010 Competitive Analysis"), concluding that the cloud market will grow Romania at least five times faster than overall IT market, the fastest growing will probably be recorded at Platform as a Service - PaaS and SaaS lowest.

The results of the "Cloud Adoption, IT Strategies from Business Perspectives" study conducted by CIO Council Romania based on a sample of 107 large companies showed that $61 \%$ of companies in Romania are using services based on cloud computing. In the opinion of experts, the remaining $39 \%$ of companies will be forced to choose and use at least one cloud service in the near future to not lose competitive advantage.

\section{Research methodolgy and results}

As cloud-based accounting solutions are serving consumers and users of financial accounting information we chose to evaluate the user experience of SaaS financial applications accessed from mobile devices from the perception $\mathrm{PhD}$ students participating in doctoral programs organized by the Academy of Economic Studies in Bucharest.

Following the distribution electronically during December 2013 - February 2014 survey conducted by the research team resulted in 40 usable responses. We consider this sample relevant for our study as it reproduces the opinions of the current generation of specialist regarding the usefulness of new technologies in the financial sector. The results of statistical processing are the following:

1. Understanding the concept of cloud computing: only $5 \%$ of respondents said they are not familiar with this concept, all of them working in the service sector.

This distribution of responses is justified by the propagation of information affecting IT industry: naturally, those working in the IT field need to update their IT skills and are often 
the first who learn of the existence of new trends in information technology. Then the information is sent to those working in areas closely associated with the IT, such as finance.

2. The company you work for uses cloud computing based accounting solutions? If yes, which type? $95 \%$ of respondents said that cloud services are used by the company they are working for. Respondents who stated that cloud services are not used by the company they are working for represent $50 \%$ of doctoral students working in services.

Respondents working in banking and accounting and 55\% of respondents working in IT are using a SaaS accounting software. $45 \%$ of respondents working in IT use an IaaS model.

3. Understanding the concept of mobile cloud computing: 67\% of respondents said they were familiar with the concept of mobile cloud computing, while $32.5 \%$ said thatit is an unknown concept.

Of the $67 \%$ of respondents who know the concept of mobile cloud computing, $11 \%$ work in banking, $43 \%$ work in accounting, $33 \%$ work in IT and 12\% work in services.

As for the concept of cloud computing, the distribution of responses is justified by the propagation of information affecting the IT industry. Although this concept is not new, he appeared in about the same period with the concept of cloud computing, it began to enjoy the intense media coverage with the advent of new generation of smart phones.

4. Cloud services used by the company for which you work can be accessed from a mobile device? If yes, what type of device? : Only $57.5 \%$ of respondents said that they can access these services using a mobile device. $65.21 \%$ of respondents use a smart phone, $34.78 \%$ are using a tablet. Out of those working in accounting, 73\% use smart phones to access the accounting app, while $27 \%$ use tablets. Respondents working in IT and banking are using smart phones and tablets evenly to access cloud services.

5. How do you access cloud services on mobile devices? : Only $30 \%$ of respondents who use mobile devices to access cloud services areusing a special application, the remaining $70 \%$ are using the device's built-in browser. $33 \%$ of smart phones users and $25 \%$ of tablet users access cloud services via an application compatible with their device.

6. What type of data connection do you use? $26 \%$ of respondents use a $3 \mathrm{G}$ connection, $8.6 \%$ use a $4 \mathrm{G}$ connection, the remaining $65.4 \%$ using a standard Wi-Fi connection to access cloud services on mobile devices.

7. How do you evaluate the performance of cloud services accessed from mobile devices? $57 \%$ of respondents said that the performance of cloud services accessed from mobile devices is lower than when accessing the same services from a PC or laptop.

$53 \%$ of smart phones users and $62.5 \%$ of tablets users consider the performance of cloud services that is lower compared to the performance obtained when accessing the service from a PC / laptop. $55 \%$ of custom app users and $56.25 \%$ of built-in browsers appreciate the performance of cloud services to be lower when compared to the performance obtained when accessing the same service from a PC / laptop. $66 \%$ of $3 \mathrm{G}$ users, $50 \%$ of $4 \mathrm{G}$ users and $53 \%$ of Wi-Fi users appreciate the performance of mobile cloud services to be lower when compared to the performance obtained when accessing the same service from a PC / laptop.

8. What are the factors that adversely affect your user experience? : For $60.86 \%$ of respondents the reduced size of the screen of the mobile device is a key factor with negative impact on the user experience. For $86.95 \%$ of the respondents, the battery life of the mobile devicehas a negative impact on the user experience. $52.17 \%$ of respondents said that they have difficulties in entering data using a mobile device when accessing cloud services. The type and characteristics of data connection used to access the cloud services reaches the highest negative impact with the user experience.

9. The advantages of using the cloud accounting services : 
- Saving time and money: Over $75 \%$ of respondents working in accounting and using cloud accounting solutions via a mobile device believe that their main advantage is saving time and money.

As shown in previous research based on the quantification in temporal terms of the processing stages of the monthly accounting flow and assuming an average price of 290 lei / month for accounting firms and an average price of 200 lei/ month for a chartered accountant for a SMEwith a business profile, the potential cost savings generated by moving the monthly accounting processing in the cloud is 217 lei / month for an accounting firm and 150 lei / month for an accountant.

- Productivity: $75 \%$ of respondents believe that the use of the cloud accounting solutions leads to increased productivity because these solutions enable fast interaction with financial accounting data by removing periodical trips to take over the primary accounting documents fromcustomers.

- Further training: $65 \%$ of respondents working in accounting and using cloud accounting solutions via a mobile device are of the opinion that the use of latest accounting applications is a mandatory requirement to maintain professional knowledge and skill at the level required by the accounting profession to ensure that the employer or client receive competent professional service. $58 \%$ of them believe that the speed at which they adapt to new trends in the accounting appsindustry is an advantage in the increasingly competitive field of accounting services.

\section{Disadvantages of using mobile cloud accounting services :}

- Performance: Over $70 \%$ of respondents who use the cloud accounting solutions available on a mobile device argue that application performance is much lower than with PC or laptop. $60 \%$ of them believe that this decrease in performance is due solely to the type of data connection, the remaining $40 \%$ are of the opinion that only the mobile device type used affects application performance.

- Data connection: For $90 \%$ of respondents who use the cloud accounting solutions available from a mobile device, the impossibility of using a $\mathrm{Wi}-\mathrm{Fi}$ while traveling is the main drawback of the mobile cloud accounting services .

- The limitations of mobile devices: For $78 \%$ of respondents, the small size of the screen of the mobile device, difficulties in entering data and limited lifetime of the battery is a disadvantage of using the cloud accounting solutions available on a mobile device.

\section{Conclusions}

The rapid evolution of the mobile market has made it a favorable environment for the spread of the concept of cloud computing. Based on the estimate that $79 \%$ of users will access the Internet on a mobile device in 2014, we have proposed evaluation of user experience financial applications running on mobile devices based on the perception $\mathrm{PhD}$ students participating in doctoral programs organized by the Academy of Economic Studies in Bucharest. Study results showed that mobile cloud computing is a concept that is becoming increasingly known in the IT environment in Romania as many companies that provide accounting services via mobile cloud being active on the market. Also, mobile devices such as smart phones and tablets are beginning to be increasingly used to access SaaS business applications instead of PCs/laptops because they provide access to data regardless of location, the main factors adversely affecting the user experience are the screen size smaller than that of aPC, the reduced battery life,the type and characteristics of the data connection.

\section{References}

1. ABI Research, http://www.abiresearch.com/, accessed on: 10.05.2013 
2. Cloud Mania, 2013. Top 5 key issues about cloud adoption in Romania according cio council study, [online], Available at: http://cloudmania2013.wordpress.com/2013/07/23/top5-key-issues-about-cloud-adoption-in-romania-according-cio-council-study/, accessed on 03.09.2013

3. Dihal S., Bouwman H., Reuver M., Warnier M., Carlsson C., 2013. Mobile cloud computing: state of the art and outlook, Vol. 15, No. 1, pp. 4-16, Q Emerald Group Publishing Limited

4. Donald A. C., Oli S. A., Arockiam L., 2013. Mobile Cloud Security Issues and Challenges: A Perspective, International Journal of Engineering and Innovative Technology (IJEIT), Vol. 3, Issue 1,, pp. 401-407

5. Huang D., Xing T., Wu H., 2013. Mobile Cloud Computing Service Models: A UserCentric Approach

6. Ionescu B., Ionescu I., Tudoran L., Bendovschi A., 2013. Traditional accounting vs. Cloud accounting, Proceedings of the 8th International Conference ACCOUNTING AND MANAGEMENT INFORMATION SYSTEMS, AMIS 2013, pp. 106-125

7. Kottari V., Kamath V., Saldanha L. P., Mohan C., 2013. A Survey on Mobile Cloud Computing: Concept, Applications and Challenges, Journal of Advanced and Innovative Research, Vol. 2 Issue 3, pp. 487-492

8. Marinelli E., 2009. Hyrax: cloud computing on mobile devices using Map Reduce, Master thesis, Carnegie Mellon University

9. Marrapese. B. , 2010. Google ceo: a few years later, the mobile phone becomes a super computer, [Online] Available: http://www.itnews-blog.com/it/21320.html, accessed on 3.08.2013

10. Park J., Yu H. C., Chung K., Lee E., 2011. Markov Chain Based Monitoring Service for Fault Tolerance in Mobile Cloud Computing, Advanced Information Networking and Applications (WAINA), 2011 IEEE Workshops of International Conference , pp. 520-525

11. Patel J. K., 2011. Adoption and Impact of E-Accounting, Golden Resrach Thoughts, pp. 1-4;

12. Shastri M. V., Patil G. V., Karande M. U., 2013. Cloud Computing Used In Mobile Network, International Journal of Research in Computer and Communication Technology, Vol. 2, Issue 4, pp. 175-179

13. Singh S., Bagga R., Singh D., Jangwal T., 2012. ARCHITECTURE OF MOBILE APPLICATION, SECURITY ISSUES AND SERVICES INVOLVED IN MOBILE CLOUD COMPUTING ENVIRONMENT, International Journal of Computer and Electronics Reasearch, Vol. 1, Issue 2, pp. 58-67

14. http://mobithinking.com/blog/mobile-web-penetration, accessed on 8.01.2014

15. http://www.emarketer.com/Article/Middle-East-Africa-Nearly-All-WebUsersMobile/1010507/2, accessed on 15.01.2014

16. http://www.gartner.com/newsroom/id/2603623, accessed on 10.10 .2013

17. http://www.idc.com/getdoc.jsp?containerId=prUS24065413, accessed on 9.05.2013

18. http://www.mobilecloudcomputingforum.com, accessed on 10.02.2014

19. http://www.zdnet.com/the-evolution-of-enterprise-software-an-overview-7000014006/, accessed on 20.06.2013

20. https://www.idc.com/getdoc.jsp?containerId=prUS24461213, accessed on 4.12.2013 